\title{
Pengaruh Ukuran Katup Terhadap Torsi Dan Daya Pada Sepeda Motor Honda Supra Fit
}

\author{
M. Debi Rahman ${ }^{1}$, N. Arya Wigraha ${ }^{2}$, G. Widayana ${ }^{3}$ \\ 1,2,3 Jurusan Pendidikan Teknik Mesin \\ Universitas Pendidikan Ganesha \\ Email: debirahma188@gmail.com ${ }^{1}$, arya_wigraha@yahoo.co.id ${ }^{2}$, \\ gedewidayana@gmail.com ${ }^{3}$
}

\begin{abstract}
ABSTRAK
Modifikasi katup bertujuan agar pemasukan campuran bahan bakar dan udara lebih banyak masuk ke ruang bakar sehingga mendapatkan efisiensi volumetrik yang ideal untuk meningkatkan performa mesin kendaraan. Penelitian ini bertujuan untuk mengetahui perbandingan ukuran katup standar dan modifikasi terhadap torsi dan daya pada sepeda motor honda supra fit. Pada penelitian ini peneliti menggunakan metode eksperimen dengan menggunakan parameter uji Dynotest. Dari hasil penelitian pengujian torsi yang telah dilakukan dimana pada kondisi katup standar menghasilkan torsi tertinggi pada 5500 RPM sebesar 4,35 N.m, sedangkan daya tertinggi diperoleh pada 7000 RPM sebesar 3,76 Hp. modifikasi menghasilkan torsi tertinggi pada 7500 RPM sebesar 5,24 N.m, sedangkan daya tertinggi diperoleh pada 8000 RPM sebesar 5,73 Hp. Dengan analisa paired sample t-test yaitu membandingkan torsi dan daya pada katup standar dan modifikasi dari hasil yang telah didapatkan dimana hasil yang lebih baik diperoleh pada modifikasi
\end{abstract}

Kata kunci : Honda supra fit, katup standar, modifikasi, daya, torsi

\section{ABSTRACT}

The valve modification aims at bringing fuel and air mixture in bigger amount into combustion chamber, so as to achieve the ideal volumetric efficiency to improve engine performance. This study aimed at determining the size to the ratio of standard valves and modification to the torque and power on the Honda Supra Fit motorcycle. In this research the researcher used experimental method by using Dynotest parameter. From the research results, the torque testing has been done where the standard valve condition producing the highest torque at 5500 RPM amounted to $4.35 \mathrm{~N} . \mathrm{m}$, while the highest power is obtained at 7000 RPM amounted to $3.76 \mathrm{Hp}$. The modification produced the highest torque at 7500 RPM of 5.24 N.m, while the highest power was obtained 8000 RPM amounted to $5.73 \mathrm{Hp}$. The data were analysed through t-test sample paired analysis which was comparing the torque and power on the standard and modified from the results of student were obtained where the better results is demonstrated in modified machine.

Keywords: Honda Supra Fit, standard valve, modivied, torque, power

\begin{abstract}
Pendahuluan
Perkembangan teknologi pada era globalisasi ini sangat pesat, dimana khususnya dalam perkembangan ilmu pengetahuan dan teknologi (IPTEK) di bidang otomotif. Pengembangan teknologi dibidang Otomotif yang semakin maju dan berkembang. Salah satunya perkembangan teknologi yang semakin maju dapat dirasakan saat ini adalah
\end{abstract}

sepeda motor. Sepeda motor merupakan alat transportasi terbanyak di Indonesia. Dimana sepeda motor dianggap lebih praktis dan lebih mudah menerjang kemacetan. Maka dari itu banyak masyarakat atau konsumen yang lebih memilih menggunakan sepeda motor dibanding menggunakan mobil atau alat transportasi lainnya.

Saat ini banyak masyarakat menjadikan sepeda motor sebagai kendaraan utama dikarenakan harganya tergolong murah, 
perawatan serta pemakaiannya yang mudah. Sepeda motor di Indonesia banyak memiliki merek-merek yang terlaris di pasaran, salah satunya adalah Honda supra fit. Sepeda motor honda supra fit dengan awal pembuatan pada tahun 2006 s/d 2010. Memiliki spesifikasi seperti, dengan bermesin 4 stroke 1 cilinder dan kapasitas mesin 100 cc yang memiliki max power 8000 rpm, max torsi $6000 \mathrm{rpm}$.

Seiring dimakannya usia dan kurang perawatan sepeda motor honda supra fit Tahun 2006 mengalami penurunan performa baik torsi maupun daya. Salah satu cara untuk menaikan performa mesin kendaraan, yaitu modifikasi katup di mana melakukan penggantian katup standar ke katup racing. Katup racing ini bertujuan untuk memperlancar aliran campuran bahan bakar ke ruang bakar.

peneliti memilih modifikasi katup menggunakan sepeda motor honda supra fit Tahun 2006 dengan cara penggantian katup hisap dan katup buang dimana ukuran standar katup hisap $21 \mathrm{~mm}$ dan katup buang $19 \mathrm{~mm}$. Dan di ganti dengan ukuran katup hisap $25 \mathrm{~mm}$ dan katup buang $21 \mathrm{~mm}$ dan di barengi dengan porting lubang hisap dan buang. Tujuan yang melatar belakangi dipilinnya modifikasi katup agar pemasukan campuran bahan bakar dan udara lebih banyak masuk ke ruang bakar sehingga mendapatkan efisiensi volumetrik yang ideal, dimana katup ( valve ) berperan sebagai pintu masuk campuran BBM ke ruang bakar. Hal ini tentunya memiliki pengaruh besar terhadap performa mesin pada kendaraan tersebut. Salah satunya adalah torsi dan daya yang dimiliki oleh sebuah mesin kendaraan. Oleh karena itu peneliti merasa perlu melakukan penelitian dengan serangkaian eksperimen untuk mengetahui pengaruh modifikasi katup terhadap Torsi dan Daya.

Berdasarkan uraian diatas maka perlu dilakukan penelitian "pengaruh perbandingan ukuran katup standar dan modifikasi terhadap torsi dan daya pada sepeda motor honda supra fit". Sehingga akan di ketahui bagaimana pengaruh modifikasi katup masuk dan katup buang terhadap torsi dan daya pada mesin honda supra fit.

\section{Motor Bensin}

Motor dengan penyalaan busi dan berbahan minyak sebagai tenaga utama ketika minyak tersebut diledakan dengan percikan api dari busi, atau disebut dengan motor bensin dengan menggunakan bahan bakar bensin (premium) yang ledakannya didalam silinder. Dalam proses pembakaran tenaga panas bahan bakar diubah ke tenaga mekanik melalui pembakaran bahan bakar di dalam motor. Pembakaran adalah proses kimia dimana karbondioksida dan zat air bergabung dengan oksigen dalam udara. Motor bensin bekerja dengan torak bolak-balik (naik turun pada motor gerak). Motor bensin bekerja menurut prinsip 4 langkah dan prinsip ini umumnya digunakan pada teknik motor bensin dan disel (Daryanto, 2003:9)

Untuk motor bensin empat langkah, bahan bakar berupa campuran bensin dengan udara dibakar untuk memperoleh energi panas dan selanjutnya energi itu diubah menjadi gerakan mekanik . Proses perubahan energi dari energi kimia sampai energi mekanik dapat dijelaskan sebagai berikut: campuran udara dan bensin dari karburator masuk melalui katup hisap kedalam silinder, kemudian torak naik dan campuran udara bensin dimampatkan, di bakar sehingga campuran akan terbakar dan menimbulkan energi panas serta tekanan yang tinggi, maka torak akan terdorong ke bawah. Jika torak tersebut dihubungkan dengan batang torak dan poros engkol, maka akan terjadi perubahan gerak dari gerakan naik turun torak diubah menjadi gerakan putar poros engkol. Gas sisa pembakaran dibuang ketika torak kembali bergerak ke atas dan di dorong keluar melalui katup buang, hal itu terjadi secara periodik.

\section{Prinsip Kerja Motor Bensin 4 Tak}

Sepeda motor yang menggunakan motor bensin 4 tak memiliki konsruksi yang terdiri dari katup hisap, katup buang, silinder, torak, cincin torak, batang torak, poros engkol, dan roda penerus (Marsudi, 2010:1)

Jurnal Pendidikan Teknik Mesin Undiksha | 46 
Didalam motor bensin 4 tak, campuran udara dan bensin dibakar untuk memperoleh tenaga panas. Perubahan tenaga panas menjadi tenaga gerak atau tenaga mekanik dapat dijelaskan sebagai berikut: ketika katup hisap membuka, campuran udara dan bensin akan masuk kedalam silinder melalui saluran katup hisap. Campuran udara dan bensin itu kemudian dimampatkan atau dikompresi dengan torak yang bergerak ke Titik Mati Atas (TMA) dan terbakar oleh percikan api dari busi, hasil pembakaran yang mempunyai temperatur dan tekanan yang tinggi itu mendorong torak ke Titik Mati Bawah (TMB), gerak torak diteruskan oleh batang torak keporos engkol untuk diubah menjadi gerak putar. Ketika katup buang membuka selanjutnya gas panas mendorong torak hingga ke Titik Mati Bawah (TMB), didorong keluar oleh torak yang bergerak ke Titik Mati Atas (TMA) ke udara luar melalui saluran buang atau knalpot.

Pada saat motor bensin 4 langkah bekerja, terjadi 4 langkah torak, yaitu: langkah hisap, langkah kompresi, langkah usaha dan langkah buang. Adapun proses yang terjadi pada masing-masing langkah tersebut adalah sebagai berikut

1. Langkah Hisap

Pada langkah ini katup isap (katup masuk) terbuka dan katup buang tertutup. Piston bergerak dari TMA (Titik Mati Atas) ke TMB (Titik Mati Bawah) poros engkol (crank shaft) bergerak 180. Gerakan tersebut menciptakan kevakuman di dalam ruang silinder yang berakibat terjadinya perbedaan tekanan antara udara di dalam silinder dengan udara di luar silinder (atmosfir lepas) hal ini menyebabkan tekanan udara di dalam silinder sangat rendah dan hal ini mengakibatkan campuran udara dan bahan bakar dari karburator terhisap masuk melalui lubang katup masuk. Ketika piston mencapai TMB (Titik Mati Bawah) katup hisap tertutup dan katup buang pun tertuttup kemudian dimulailah langkah kompresi (Marsudi, 2010:8).

2. Langkah Kompresi
Setelah torak menyelesaikan langkah isap, posisi piston yang berada di TMB (Titik Mati Bawah) bergerak ke TMA (Titik Mati Atas) dan crank shaft berputar 180, katup masuk menutup begitupun dengan katup buang masih dalam keadaan menutup, gerakan piston ke atas menyebabkan campuran udara yang berada di dalam silinder dikompresikan atau dimampatkan. Selaras dengan aksi kompresi tersebut, selama proses kompresi, suhu campuran udara dan bahan bakar meningkat mencapai ratusan derajat, hal ini sangat penting dan mempengaruhi pembakaran campuran udara dan bahan bakar. Beberapa saat sebelum piston mencapai TMA, busi memercikan bunga api listrik sehingga gas yang telah mencapai temperatur dan tekanan yang tinggi itu akan terbakar.

3. Langkah Usaha atau Ekspansi

Pada langkah usaha atau ekspansi terjadi proses kerja sebagai berikut, torak bergerak dari TMA (Titik Mati Atas) ke TMB (Titik Mati Bawah), poros engkol berputar setengan lingkaran 180, posisi katup hisap dan katup buang masih dalam keadaan tertutup kemudian karena pembakaran tersebut bertekanan dan temperatur di dalam silinder menjadi tinggi sehingga mendorong piston bergerak dari TMA (Titik Mati Atas) ke TMB (Titik Mati Bawah) saat inilah tenaga panas dirubah menjadi tenaga gerak atau tenaga mekanik sehinga menghasilkan usaha atau ekspansi, tenaga gerak piston disalurkan batang piston ke poros engkol dan diubah menjadi tenaga gerak berputar, saat piston berada di TMB (Titik Mati Bawah), katup isap masih dalam keadaan tertutup sedang katup buang mulai terbuka.

4. Langkah Buang

Pada langkah buang terjadi proses kerja sebagai berikut, torak bergerak dari TMB (Titik Mati Bawah) ke TMA (Titik Mati Atas), poros engkol (crank shaft) berputar setengah lingkaran 180 dan katup isap masih dalam kedaan tertutup dan katup buang terbuka, 
piston mendorong gas sisa pembakaran keluar dari ruang silinder melalui saluran buang terus ke udara luar melalui knalpot.

Setelah langkah buang selesai, yaitu pada saat piston berada di TMA (Titik Mati Atas) katup isap mulai terbuka dan katup buang kembali tertutup. Siklus berikutnya dimulai lagi denang mengulangi langkah-langkah yang sama pada siklus di atas (Marsudi, 2010:8).

Dari uraian diatas bahwa ciri-ciri motor bensin 4 langkah sebagai berikut:

a. Pada setiap silinder sekurangkurangnya terdapat dua katup, yaitu katup hisap dan katup buang.

b. Pada setiap siklus, poros engkol (crank shaft) berputar 180 dan piston bergerak dari TMA ke TMB atau dari TMB ke TMA.

c. Setiap putaran crank shaft 180 poros nok hanya berputar 90 . Untuk menghasilkan satu kali usaha kerja dari keseluruhan langkah kerja crank shaft berputar 720 dan poros nok berputar 360.

\section{Mekanisme Katup}

Mesin 4 tak mempunyai langkah hisap, langkah kompresi, langkah usaha dan langkah buang. Kerja katup hanya dibutuhkan dalam 2 proses langkah, yaitu langkah hisap dan langkah buang. Mekanisme katup ini dirancang sedemikian rupa sehingga poros nok berputar satu kali untuk menggerakkan katup hisap dan katup buang setiap 2 kali putaran poros engkol.

\section{Unit Katup}

Unit katup untuk membuka dan menutup saluran hisap disebut unit katup hisap sedang unit katup untuk menutup dan membuka saluran buang disebut katup buang Susunan pokok bagian-bagian unit katup terdiri dari:
a) Katup (valve)
b) Pegas Katup (valve spring)
c) Bos Katup (valve guide)
d) Pengukuh (retainer)
e) Penutup Celah (split keepers)
f) Ring dudukan

\section{Katup}

Katup (valve) dibedakan menjadi 2 macam, yaitu katup hisap dan katup buang. Untuk membedakan antara katup hisap dan katup buang dapat dilihat ukuran diameter kepala katupnya (valve head). Ukuran diameter katup hisap bila dibandingkan dengan ukuran diameter katup buang adalah lebih besar, yaitu agar dapat meningkatkan efisiensi pengisian campuran udara dan bensin ke dalam silinder (dalam Marsudi 2010:43). Kepala katup mempunyai bentuk kerucut dengan sudut 45. Pada saat tertutup, katup menempel dengan rapat pada dudukan katup. Batang katup bergerak dalam bos katup (valve guide). Pada ujung bagian atas terdapat alur untuk tempat pemasangan spring retainer, yang selanjutnya dikunci dengan penutup celah.

a. Pegas Katup

Pegas katup (valve spring) merupakan pegas spiral untuk menutup katup lagi setelah pelatuk katup (roker arm) bergerak menjauhi batang katup. Pegas katup pada masing-masing katup ada 2 macam, yaitu pegas katup luar (valve ex) dan pegas katup bagian dalam (valve in), yang mempunyai tegangan berbeda. Pegas katup dibuat dari campuran baja sehingga memiliki ketahanan yang tinggi terhadap kelelahan.

Gaya yang diperlukan untuk menutup katup oleh pegas tidak perlu tinggi, tetapi cukup menutup katup dengan rapat pada dudukannya dan dapat mengatasi gaya kelembaban mekanis katup dengan gerakan cepat. Pegas katup, yang terdiri dari 2 gulungan spiral, kedua-duanya diapit diantara 2 ring dudukan pegas katup. Pada pemasanganya, kedua pegas dipasang saling berlawanan arah agar tidak saling bertabrakan satu sama lain. Apabila tegangan pegas lemah, gas mungkin akan keluar sehingga tenaga mesin jadi berkurang.

b. Bos Katup

Bos katup (valve guide) atau jalan katup berfungsi untuk bantalan katup, dibuat dari logam yang memiliki sifat sebagai penghantar panas yang baik dan tahan aus. Panas batang katup dapat dihantarkan oleh bos katup ke kepala silinder.

Bos katup dipasang pada kepala silinder dengan cara disusutkan. Caranya, kepala silinder dipanaskan terlebih dahulu 
sehingga lubang tempat bos katup bertambah besar, baru kemudian bos katup dipasang dengan cara ditekan.

c. Dudukan Katup

Dudukan katup pada kepala silinder berbentuk cincin yang dipasang dengan teknik tekan. Permukaan diasah dengan sudut sesuai kepala katup yaitu 45 . Permukaan dudukan katup harus halus dan rapat terhadap katupnya agar tidak terjadi kebocoran. Antara dudukan katup dan kepala katup biasa dilakukan skuur klep (valve grinding) menggunakan amril pengasah. Tujuannya adalah untuk menghasilkan kerapatan.

\section{Waktu Kerja Katup}

Masa kerja katup (valve timing) adalah saat membuka dan menutupnya katup yang berhubungan dengan posisi penggerak torak. Pada saat mesin berputar dengan kecepatan tinggi maka katup harus membuka lebih cepat dan menutup lebih lambat. Hal ini untuk memberikan kesempatan bagi masuknya campuran udara dan bensin ke dalam silinder sebanyak mungkin.

Sebaliknya, katup buang akan membuka sebelum langkah usaha berakhir dan tetap terbuka sampai beberapa saat setelah langkah hisap dimulai. Masa kerja katup dinyatakan dalam bentuk yang menunjukkan besarnya sudut perputaran poros engkol berdasarkan kedudukan torak pada TMA atau TMB.

Waktu buka dan tutup katup berpengaruh terhadap performa mesin. Adapun besar durasi yang sesuai dengan performa mesin seperti:

1. Performa mesin low speed pada motor kompetisi buka tutup katup kisaran $20^{\circ}$ 50 untuk katup intake membuka dan menutup, dan 50-20 katup exhaust membuka dan menutup.

2. Performa mesin sport untuk katup intake membuka dan menutup kisaran 25-65 dan katup exhast membuka dan menutup kisaran $70^{\circ}-20^{\circ}$.

3. Performa mesin full maxsimum speed untuk katup intake membuka dan menutup kisaran $40^{\circ}-70^{\circ}$ dan katup exhaust membuka dan menutup kisaran 75-35 (Graham bell, 1998: 342).

\section{MV ( Multi Valve )}

Merupakan mekanisme katup dengan jumlah katup tiap silinder lebih dari satu pasang atau lebih dari dua buah. Tujuan multi valve adalah meningkatkan efisiensi volumetrik dan performa mesin dengan cara memperbesar saluran pemasukan dan pembuangan. Sukma Catur ( 2014 )

Memperbesar katup standar tentu akan menambah efisiensi volumetrik dan performa mesin baik torsi maupun daya. Dengan demikian, akan menimbulkan pembakaran yang lebih besar sehingga mendongkrak performa mesin. Memperbesar katup juga tidak boleh sembarangan berikut rumus hitung untuk mencari diameter katup. Graham Bell. (1998).

1. Mencari ukuran diameter ideal katup in (masuk) adalah : 50\% ( efisiensi volumetrik ) x Diameter piston.

2. Sedangkan untuk katup ex (buang) adalah : 85\% (efisiensi volumetrik ) $x$ diameter katup masuk

\section{Torsi Kendaraan}

Torsi adalah ukuran kemampuan mesin untuk melakukan kerja, jadi torsi adalah suatu energi. Besaran torsi adalah besaran turunan yang biasa digunakan untuk menghitung energi yang dihasilkan dari benda yang berputar pada porosnya. Adapun perumusan dari torsi adalah sebagai berikut. Apabila suatu benda berputar dan mempunyai besar gaya sentrifugal sebesar $F$, benda berputar pada porosnya dengan jari-jari sebesar $b$, dengan data tersebut torsinya adalah:

$\mathrm{T}=\mathrm{F} \times \mathrm{d}(\mathrm{N} . \mathrm{m})$

dimana:

$\mathrm{T}=$ Torsi benda berputar (N.m)

$\mathrm{F}=$ adalah gaya sentrifugal dari benda yang berputar $(\mathrm{N})$

$\mathrm{d}=$ adalah jarak benda ke pusat rotasi $(\mathrm{m})$

Karena adanya torsi inilah yang menyebabkan benda berputar terhadap porosnya, dan benda akan berhenti apabila ada usaha melawan torsi dengan besar sama dengan arah yang berlawanan.

Pada motor bakar untuk mengetahui daya poros harus diketahui dulu torsinya. Pengukuran torsi pada poros motor bakar menggunakan alat yang dinamakan Dynotest. Prinsip kerja dari alat ini adalah dengan memberi beban 
yang berlawanan terhadap arah putaran sampai putaran mendekati $0 \mathrm{rpm}$, Beban ini nilainya adalah sama dengan torsi poros. Saat mesin dinyalakan kemudian pada poros disambungkan dengan dinamometer. Untuk megukur torsi mesin pada poros mesin diberi rem yang disambungkan dengan (w) pengereman atau pembebanan. Pembebanan diteruskan sampai poros mesin hampir berhenti berputar. Beban maksimum yang terbaca adalah gaya pengereman yang besarnya sama dengan gaya putar poros mesin F. Dari definisi disebutkan bahwa perkalian antara gaya dengan jaraknnya adalah sebuah torsi, dengan definisi tersebut Torsi pada poros dapat diketahui dengan rumus: $\mathrm{T}=\mathrm{w} \times \mathrm{d}(\mathrm{Nm})$

dengan :

$\mathrm{T}=$ adalah torsi mesin $(\mathrm{Nm})$

$\mathrm{w}=$ adalah beban $(\mathrm{N})$

$\mathrm{d}=$ adalah jarak pembebanan dengan pusat perputaran (m)

Ingat (w) beban/berat disini kita bedakan dengan massa $(\mathrm{m})$, kalau massa satuan $\mathrm{kg}$, adapun beban disini adalah gaya berat dengan satuan $\mathrm{N}$ yang diturunkan dari $W=m g$

\section{Daya Kendaraan}

Sedangkan power yang dihitung dengan satuan Kw (Kilo watts) atau Horse Power (HP) mempunyai hubungan erat dengan torsi. Power dirumuskan sbb :

Power $=$ torsi $\mathrm{x}$ angular speed.

Rumus diatas adalah rumus dasarnya, pada engine maka rumusnya menjadi :

Power $=$ torsi $\times 2$ phi $\times$ rotational speed (RPM).

Untuk mengukur Power (KW) adalah sbb : Power $(\mathrm{kW})=$ torsi $(\mathrm{Nm}) \times 2$ phi $\mathrm{x}$ rotational speed (RPM) / 600006000 dapat diartikan adalah 1 menit $=60$ detik, dan untuk mendapatkan $\mathrm{kw}=1000$ watt.

sedangkan untuk mengukur Power (HP) adalah sbb :

Power $(\mathrm{HP})=$ torsi $($ lbs. $\mathrm{ft}) \times$ rotational speed (RPM)

Pada motor bakar, daya dihasilkan dari proses pembakaran didalam silinder dan biasanya disebut dengan daya indiaktor. Daya tersebut dikenakan pada piston yang bekerja bolak balik didalam silinder mesin. Jadi didalam silinder mesin, terjadi perubahan energi dari energi kimia bahan bakar dengan proses pembakaran menjadi energi mekanik pada piston. Daya indikator adalah merupakan sumber tenaga persatuan waktu operasi mesin untuk mengatasi semua beban mesin. Mesin selama bekerja mempunyai komponen-komponen yang saling berkaitan satu dengan lainnya membentuk kesatuan yang kompak.

\section{Metode}

\section{Tempat dan Waktu Penelitian}

Pelaksanaan eksperimen dan pengambilan data dalam penelitian ini dilakukan Pada Ruang uji akselerasi sepeda motor, Trimurti Abiyasa Motor, Singaraja, Waktu penelitian ini dilakukan pada semester genap 2016/2017.

\section{Rancangan Penelitian}

Metode yang akan digunakan dalam penelitian ini adalah metode eksperimen. Menurut Sugiono (2004) Penelitian ekperimen adalah penelitian yang berusaha mencari pengaruh variabel tertentu terhadap variabel lain dalam kondisi yang terkontrol secara ketat.

\section{Obyek Penelitian}

Obyek utama dalam penelitian ini yaitu mengetahui torsi dan daya motor bakar 4 tak dengan pengaplikasian katup standart dan modifkasi yang memiliki ukuran katup masuk $25 \mathrm{~mm}$ dan katup buang $21 \mathrm{~mm}$ pada motor Honda supra fit, antara lain adalah :

a. Torsi

Tujuan dari pengamatan Torsi yaitu apakah ada kenaikan atau penurunan torsi dengan modifikasi ukuran katup.

b. Daya

Tujuan dari pengamatan Daya yaitu apakah ada kenaikan atau penurunan daya dengan modifikasi ukuran katup.

\section{Variabel Penelitian}

Variabel adalah obyek penelitian, atau apa yang menjadi titik perhatian suatu penelitian (Arikunto, 2006: 118). Dalam penelitian terdapat tiga variabel, yaitu :

1. Katup standard dan modifkasi.

2. Torsi ( $\mathrm{Y} 1=$ variabel terikat).

3. Daya ( $\mathrm{Y} 2=$ variabel terikat). 


\section{Teknik Pengumpulan Data}

Teknik pengumpulan data dari peneliti ini adalah menggunakan teknik:

a. Observasi

Pengamatan melibatkan semua indera (penglihatan, pendengaran, penciuman, pembau, perasa). Peneliti melakukan pencatatan hasil dapat dilakukan dengan bantuan alat rekam elektronik

b. Dokumentasi

Dokumentasi merupakan catatan peristiwa yang sudah berlalu. Dokumentasi bisa berbentuk tulisan, gambar, atau karya karya monumental dari seseorang. Peneliti mencatat hal-hal terpenting dalam setiap tahap penelitian dan mendokumentasikan dalam bentuk gambar dari setiap obyek yang diteliti..

c. Uji laboratorium

Data uji daya dan torsi dilakukan pengujian di laboratorium atau bengkel Ruang uji akselerasi sepeda motor, Tam Motor, Singaraja, Bali. Data yang diperoleh dari hasil pengujian kemudian dianalisis dimasukkan ke dalam tabel dan ditampilkan dalam bentuk grafik, dan selanjutnya dilakukan analisis statistic ttest kemudian disimpulkan hasilnya.

\section{Diagram alir}

Penelitian merupakan langkah - langkah yang akan dilakukan selama penelitian, penelitian dilakukan secara sistematis dan berurutan, yaitu berupa Studi Literatur, tahap perancangan alat, pengadaan bahan dan alat pendukung, berupa alat ukur, kemudian tahap perakitan alat, pengujian hingga hasil.

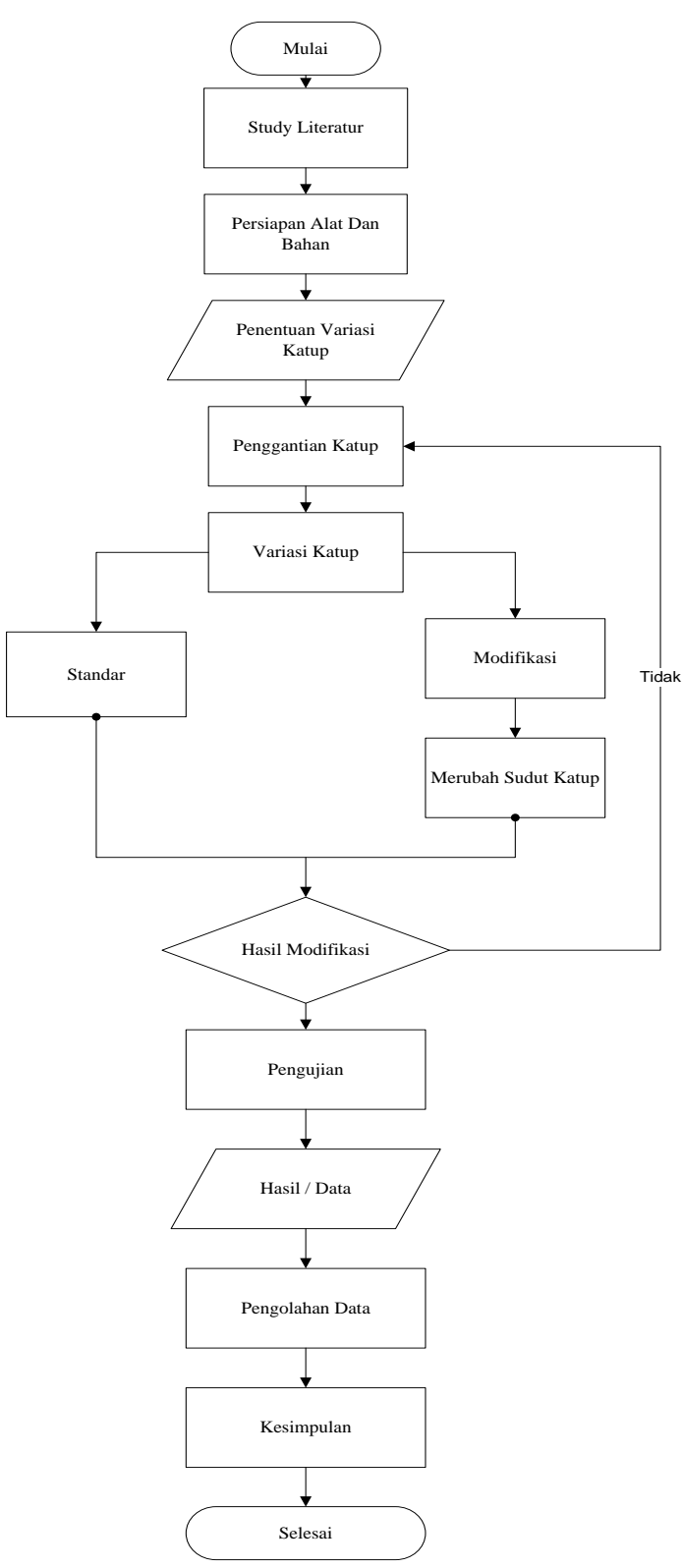

\section{Bahan Dan Alat}

a. Tool Box

b. Kepala Silinder Standar

c. Kepala Silinder dengan katup modifikasi

d. Mesin motor yang digunakan untuk penelitian adalah sepeda motor Honda supra fit.

\section{Hasil Dan Pembahasan \\ Hasil Penelitian}

Data yang diperoleh dari eksperimen berupa data hasil daya dan torsi dari mesin sepeda motor yang diuji pada dynotest, kemudian diolah lebih lanjut 
menjadi torsi dan daya. Data yang diperoleh masih berupa :

a. Putaran mesin dalam satuan revolutian per minute (RPM).

b. Torsi dalam satuan Newton meter (Nm).

c. Daya dalam satuan horse power (HP)

Alasan menggunakan kendaraan sepeda motor dalam penelitian ini karena peneliti ingin mengetahui apakah ada pengaruh perbandingan ukuran katup standar dan katup modifikasi terhadap torsi dan daya pada sepeda motor honda supra fit. Kesimpulan dari penelitian ini yaitu perbedaan peforma baik torsi dan daya motor yang masih menggunakan katup standar dan menggunakan modifikasi. dapat dilihat dari hasil tabel berikut ini. Data hasil penelitian di catat pada lembar observasi dan penelitian kemudian ditabulasikan pada tabel berikut ini.

Hasil data penelitian torsi dan daya.

\begin{tabular}{|c|c|c|c|c|}
\hline \multirow{2}{*}{ RPM } & \multicolumn{4}{|c|}{ VARIABEL } \\
\cline { 2 - 5 } & $\begin{array}{r}\text { KATUP } \\
\text { STANDAR }\end{array}$ & \multicolumn{2}{c|}{$\begin{array}{c}\text { KATUP } \\
\text { MODIFIKASI }\end{array}$} \\
\cline { 2 - 5 } & TORSI & DAYA & TORSI & DAYA \\
\hline 5000 & 4,27 & 3,00 & 4,30 & 3,03 \\
\hline 5500 & 4,35 & 3,40 & 4,28 & 3,30 \\
\hline 6000 & 4,23 & 3,60 & 4,80 & 4,13 \\
\hline 6500 & 4,09 & 3,73 & 5,11 & 4,70 \\
\hline 7000 & 3,84 & 3,76 & 5,20 & 5,13 \\
\hline 7500 & 3,53 & 3,73 & 5,24 & 5,56 \\
\hline 8000 & 3,21 & 3,63 & 5,09 & 5,73 \\
\hline
\end{tabular}

Data hasil pengujian torsi katup standar dan katup modifikasi.

\begin{tabular}{|l|c|c|}
\hline \multirow{2}{*}{ RPM } & \multicolumn{2}{|c|}{ TORSI(N.m) } \\
\cline { 2 - 3 } & $\begin{array}{c}\text { KATUP } \\
\text { STANDAR }\end{array}$ & $\begin{array}{c}\text { KATUP } \\
\text { MODIFIKASI }\end{array}$ \\
\hline 5000 & 4,27 & 4,30 \\
\hline 5500 & 4,35 & 4,28 \\
\hline 6000 & 4,23 & 4,80 \\
\hline 6500 & 4,09 & 5,11 \\
\hline 7000 & 3,84 & 5,20 \\
\hline 7500 & 3,53 & 5,24 \\
\hline 8000 & 3,21 & 5,09 \\
\hline
\end{tabular}

Torsi maksimum yang dicapai dari katup standar dan katup modifikasi adalah:
(Hasil Torsi yang dihasilkan terlampir pada Hasil Print Out Pengujian Dynotest )

a) Katup standar : 4,35 N.m / 5500 Rpm

b) Katup modifikasi : 5.24 N.m / 7500 Rpm

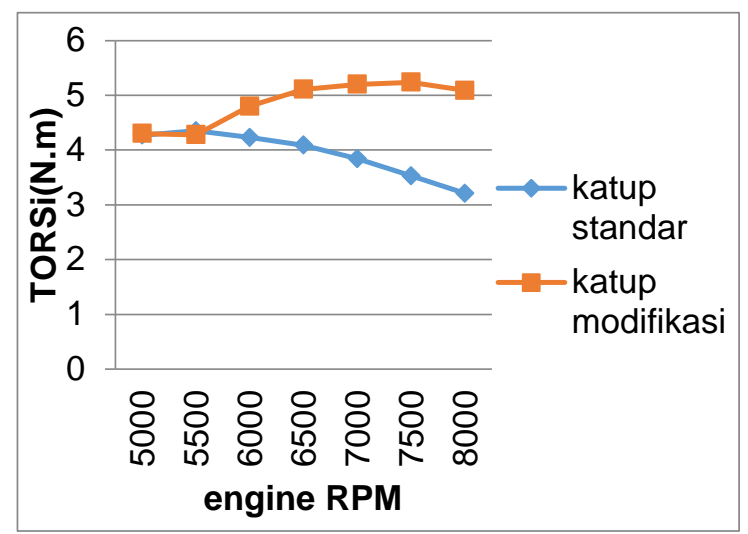

bahwa adanya perbedaan antara torsi pada motor kondisi katup standar dan katup modifikasi. pada Rpm 5500 pada katup standar sedikit meningkat dibanding katup modifikasi. Kemudian semakin rpm di naikan torsi dengan katup modifikasi cendrung mengalami peningkatan Torsi maksimum berada di $7500 \mathrm{rpm}$ sebesar 5,24 Nm dan torsi minimum berada di $5500 \mathrm{rpm}$ sebesar 4,28 Nm. Sedangkan torsi maksimum pada motor kondisi katup standar berada di $5500 \mathrm{rpm}$ sebesar $4,35 \mathrm{Nm}$. dan torsi minimum berada di $8000 \mathrm{rpm}$ sebesar 3,21 Nm. Kesimpulan dari gambar grafik perbedaan torsi motor yang menggunakan katup standar dan yang menggunakan katup modifikasi. Dalam pengujian motor yang menggunkan katup modifikasi memiliki torsi yang lebih tinggi dari pada motor yang menggunakan katup standar. hanya saja di RPM 5500 daya katup standar sedikit meningkat di bandingkan dengan katup modifikasi.

\section{Hasil pengujian dan analisa Torsi}

Hasil Pengujian pada sepeda motor yang menggunakan katup standar dan katup modifikasi dengan menggunakan alat pengujian yaitu dynotest dengan mengukur torsi sepeda motor. hasil pengujian pada sepeda motor yang menggunakan katup standar menunjukan. pada Rpm 5500 pada katup standar sedikit meningkat dibandingkan dengan katup modifikasi. Kemudian semakin rpm 
di naikan torsi dengan katup modifikasi cendrung mengalami peningkatan Torsi maksimum berada di $7500 \mathrm{rpm}$ sebesar $5,24 \mathrm{Nm}$ dan torsi minimum berada di $5500 \mathrm{rpm}$ sebesar 4,28 Nm. Sedangkan torsi maksimum pada motor kondisi katup standar berada di $5500 \mathrm{rpm}$ sebesar 4,35 $\mathrm{Nm}$. dan torsi minimum berada di 8000 rpm sebesar 3,21 $\mathrm{Nm}$ Jadi dapat disimpulkan dari pengujian dan analisa torsi pada motor, perbedaan torsi pada kondisi katup standar dan katup modifikasi, dalam pengujian dengan katup modifikasi memiliki torsi yang lebih besar dibandingkan motor dengan katup standar hanya saja pada Rpm 5500 katup standar sedikit meningkat dari katup modifikasi. Pengujian pada statistik t-test juga menunjukkan perbedaan yang signifikan antara torsi dengan katup standar dibandingkan dengan katup modifikasi Dari uji $t$-test menunjukan perbedaan yang signifikan.

Data hasil pengujian daya katup standar dan katup modifikasi

\begin{tabular}{|c|c|c|}
\hline \multirow{2}{*}{ RPM } & \multicolumn{2}{|c|}{ DAYA (HP) } \\
\cline { 2 - 3 } & $\begin{array}{l}\text { KATUP } \\
\text { STANDAR }\end{array}$ & $\begin{array}{l}\text { KATUP } \\
\text { MODIFIKASI }\end{array}$ \\
\hline 5000 & 3,00 & 3,03 \\
\hline 5500 & 3,40 & 3,30 \\
\hline 6000 & 3,60 & 4,13 \\
\hline 6500 & 3,73 & 4,70 \\
\hline 7000 & 3,76 & 5,13 \\
\hline 7500 & 3,73 & 5,56 \\
\hline 8000 & 3,63 & 5,73 \\
\hline
\end{tabular}

Daya maksimum yang dicapai dari katup standar dan katup modifikasi adalah : ( Hasil Daya yang dihasilkan terlampir pada Hasil Print Out Pengujian Dynotest )

a) Katup standar : 3,76 Hp / $7000 \mathrm{Rpm}$

b) Katup modifikasi : 5,73 Hp/ $8000 \mathrm{Rpm}$

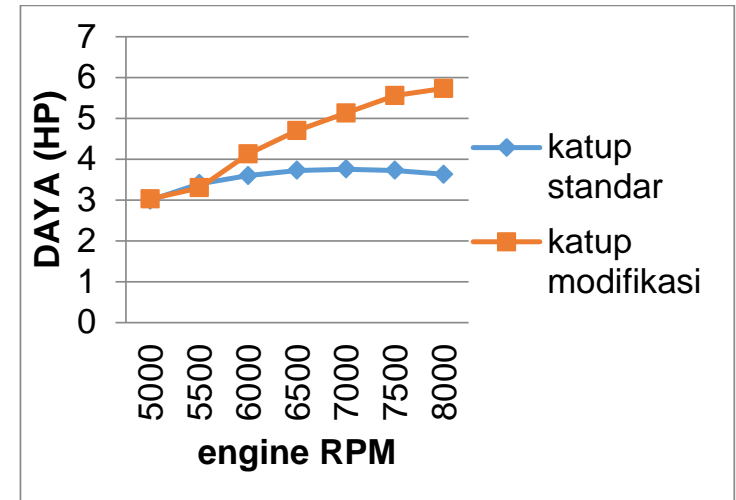

Menunjukan bahwa adanya perbedaan antara daya motor Standar dan katup modifikasi. Pada Rpm 5500 pada katup standar sedikit meningkat dibanding dengan katup modifikasi. Kemudian semakin rpm di naikkan daya dengan katup modifikasi cenderung mengalami peningkatan daya maksimum terjadi pada Rpm 8000 sebesar 5,73 HP dan daya minimum terjadi pada $5000 \mathrm{rpm}$ sebesar 3,03 Hp. Sedangkan daya dengan katup standar terjadi peningkatan daya maksimum pada 7000 rpm sebesar 3.76 HP, dan terjadi daya minimum pada 5000 rpm sebesar 3,00 HP. Kesimpulan dari grafik perbedaan daya pada kondisi katup standar dan katup modifikasi. dalam pengujian menggunakan katup modifikasi daya yang lebih besar dibandingkan motor dengan kondisi katup standar. hanya saja di RPM 5500 daya katup standar sedikit meningkat di bandingkan dengan katup modifikasi.

\section{Hasil pengujian dan analisa Daya}

Hasil Pengujian pada sepeda motor yang menggunakan katup standar dan katup modifikasi dengan menggunakan alat pengujian yaitu dynotest dengan mengukur torsi sepeda motor. hasil pengujian pada sepeda motor yang menggunakan katup standar menunjukan. Pada Rpm 5500 pada katup standar sedikit meningkat dibanding dengan katup modifikasi. Kemudian semakin rpm di naikkan daya dengan katup modifikasi cenderung mengalami peningkatan daya maksimum terjadi pada Rpm 8000 sebesar 5,73 HP dan daya minimum terjadi pada $5000 \mathrm{rpm}$ sebesar 3,03 $\mathrm{Hp}$. Sedangkan daya dengan katup standar terjadi peningkatan daya maksimum pada 7000 rpm sebesar $3.76 \mathrm{HP}$, dan terjadi 
daya minimum pada 5000 rpm sebesar 3,00 HP. Jadi dapat disimpulkan dari pengujian dan analisa daya pada motor, perbedaan daya pada kondisi katup standar dan katup modifikasi, dalam pengujian dengan katup modifikasi memiliki daya yang lebih besar dibandingkan motor dengan katup standar hanya saja pada Rpm 5500 katup standar sedikit meningkat dari katup modifikasi. Pengujian pada statistik t-test juga menunjukkan perbedaan yang signifikan antara daya dengan katup standar dibandingkan dengan katup modifikasi Dari uji $t$-test menunjukan perbedaan yang signifikan.

\section{Kesimpulan}

Bedasarkan data hasil pengujian pengaruh penggantian ukuran payung katup terhadap daya dan torsi pada kendaraan sepeda motor honda supra fit maka dapat disimpulkan bahwa :

1. Terdapat perbedaan yang signifikan pada torsi motor. Torsi dengan katup modifikasi cendrung mengalami peningkatan Torsi maksimum berada di $7500 \mathrm{rpm}$ sebesar 5,24 $\mathrm{Nm}$ dan torsi minimum berada di $5500 \mathrm{rpm}$ sebesar 4,28 Nm. Sedangkan torsi maksimum pada motor kondisi katup standar berada di $5500 \mathrm{rpm}$ sebesar 4,35 Nm. dan torsi minimum berada di $8000 \mathrm{rpm}$ sebesar 3,21 Nm.

2. Terdapat perbedaan yang signifikan pada daya motor. daya dengan katup modifikasi cenderung mengalami peningkatan daya maksimum terjadi pada Rpm 8000 sebesar 5,73 HP dan daya minimum terjadi pada 5000 rpm sebesar 3,03 Hp. Sedangkan daya dengan katup standar terjadi peningkatan daya maksimum pada 7000 rpm sebesar 3.76 HP. dan terjadi Daya minimum pada 5000 Rpm sebesar 3,00 HP.

\section{Saran dan Harapan}

Penggantian katup standar dengan katup modifikasi bertujuan untuk meningkatkan kinerja motor terutama motor standar semua jenis. penggantian ukuran katup harus sesuai kebutuhan jika ukuran katup terlalu besar motor akan tiba tiba kehilangan kinerja mesin di putaran atas. Selain itu harapan terbesar penulis dari penulis, semoga sebagian ataupun seluruh isi dari skripsi ini dapat bermanfaat dan berguna bagi penulis, lembaga, adik tingkat, maupun masyarakat lainnya.

\section{DAFTAR RUJUKAN}

PT. Astra Honda Motor, 2002 . Spesifikasi Motor Honda Supra fit, Jakarta Indonesia.

Arismundar, Wiranto.(2002). Motor Bakar Torak. Bandung : Penerbit ITB.

Daryanto.(2003). Motor Bensin Pada Mobil. Bandung: Penerbit Yrama Widya.

Sugiono, 2004, Statistika untuk Penelitian, Cetakan Keenam, Penerbit Alfabeta, Bandung.

Marsudi.(2010). Teknisi Otodidak Sepeda Motor Belajar Teknik dan Perawatan Kendaraan Ringan Mesin 4 Tak. Yogyakarta: Penerbit Andi.

Sukma Catur, Mekanisme Katup Sepeda Motor 4tak Widyaiswara Madya VEDC Malang 2014

Bell Graham. (1998). Four-Stroke Performance Tuning Third Edition. California: Haynes Publishing.

Arikunto, Suharsimi. 2006. Prosedur Penelitian (Suatu Pendekatan Praktik).

I Made Candiasa. 2011. Statistik Multivariat Disertai Aplikasi SPSS.

Eko susanto. 2011. Modifikasi Sudut Katup dan Poros Nok Motor Supra $x$ untuk Meningkatkan Performa Mesin. Jurnal Penelitian Program Studi Teknik Otomotif Fakultas Teknik Universitas Negeri Yogyakarta

Paul James Huang's. 2016 . Pengaruh Pengurangan Diameter Valvestem Dan Penambahan Radius Valveneck Terhadap Performa Motor Bakar Honda Supra Fit 100 cc

Fatwa Tresna Radityan, Wowo Sunaryo K, Ridwan Adam M. Noor . 2015. Analisis Modifikasi Mekanisme Katup Pada Engine 5tl 